\title{
Powering and puzzling: climate change adaptation policies in Bangladesh and India
}

\author{
Ryan Stock ${ }^{1}$ (D) $\cdot$ Sumit Vij ${ }^{2,3}$ (D) Asif Ishtiaque ${ }^{4,5}$ (D)
}

Received: 11 January 2019 / Accepted: 9 March 2020 / Published online: 14 March 2020

(c) The Author(s) 2020

\begin{abstract}
South Asia is a region uniquely vulnerable to climate-related impacts. Climate change adaptation in India and Bangladesh evolves using powering and puzzling approaches by policy actors. We seek to answer the question: how do powering and puzzling approaches influence the climate change adaptation policy design and implementation processes in Bangladesh and India? We adopted two strategies to collect and analyze data: semistructured interviews and discourse analysis. We found that adaptation policymaking is largely top-down, amenable to techno-managerial solutions, and not inclusive of marginalized actors. In Bangladesh, power interplays among ministerial agencies impair the policy implementation process and undermine the success of puzzling. Local-scale agencies do not have enough authority or power to influence the overall implementation processes occurring at higher scales of governance. The powering of different actors in Bangladesh is visible through a duality of mandates and a lack of integration of climate adaptation strategies in different government ministries. The powering aspect of India's various adaptation policies is the lack of collective puzzling around the question of differentiated vulnerability by axes of social difference. Paradoxically, India has a puzzling approach of hiding behind the poor in international negotiations. Moving forward, both countries should strive to have more inclusive and equitable adaptation policymaking processes that enable the participation of marginalized populations and represent their anxieties and aspirations. Identifying policy-relevant insights from South Asia using the powering and puzzling approaches can foster adaptation policy processes that facilitate empowerment, the missing piece of the adaptation policymaking puzzle.
\end{abstract}

Keywords Climate change adaptation · Powering · Puzzling · South Asia · Bangladesh · India

Disclaimer: The views expressed in this work are those of the creators and do not necessarily represent those of the UK Government's Department for International Development, the International Development Research Centre, Canada, or its Board of Governors, the US Department of State, the US Department of Education, the Fulbright Commission, the Women and Gender in Global Perspectives program, Northern Michigan University, Wageningen University, Arizona State University or the Indian Institute of Management Ahmedabad.

Sumit Vij

sumit.vij@wur.nl

Extended author information available on the last page of the article 


\section{Introduction}

Climate change adaptation is an increasingly politicized and contested policy topic in countries such as Bangladesh and India (Jaeger and Michaelowa 2016; Nightingale 2017; Sovacool 2018). Specifically, the framing of problems and adaptation solutions is among the most contested aspects of climate change policymaking (Vij et al. 2018; Rashid 2011; Ribot 2014). In these complex political realms, adaptation framing and solutions evolve using both powering and puzzling modalities. Hugh Heclo (1974) theorized that "politics finds its sources not only in power but also in uncertainty-governments while formulating policies not only 'power' but also 'puzzle"'. Powering refers to the exercise of power and authority by an actor for attaining certain solutions to a social problem (Vink et al. 2014; van der Steen et al. 2016). Puzzling refers to the exploration of different options and perspectives for a problem for the purposes of decision-making in a policy domain, based on different knowledge systems (Hoppe 2011; see also Visser and Hemerijck 1997; Culpepper 2002). Policymaking processes on climate change adaptation transpire using a mix of powering and puzzling.

Following the IPCC (2014), climate adaptation can be defined as an "adjustment in human and natural systems in response to actual or expected climate stimuli or their effects which moderate harm or exploit beneficial opportunities" (IPCC 2014). This research seeks to understand puzzling and powering characteristics within planned adaptation initiatives via formal state programs, as opposed to autonomous adaptation initiatives enabled or prevented by latent conditions (Smit and Wandel 2006). This article will focus on planned adaptation initiatives in Bangladesh and India. Powering can be observed in planned adaptation policies by observing which actor dominates the framing of adaptation and related solutions. Hall (1993) explains this aspect of powering as an ability to mobilize enough support for an interpretation of the problem and of the solution-constructing "power coalitions."

Scholars have recently used the powering and puzzling framework to illuminate adaptation policymaking processes. Hoppe (2010) used the powering and puzzling framework to investigate scale asymmetries at the boundary of science and politics within the policymaking domain of climate change. Vink et al. (2013) conducted a systematic literature review that details the complexity of adaptation governance, suggesting that the powering and puzzling framework holds promise in revealing solutions to policymaking impasses. In the context of flooding attributed to climate change, Vink et al. (2013) utilized the powering and puzzling framework to provide insights on framing water management policy proposals in the Netherlands. Vink et al. (2015) compared water management strategies of the UK and the Netherlands utilizing the powering and puzzling framework. Through their investigation of the successful powering and puzzling processes involved in the prolific Netherlands' 2008 Delta Committee, van der Steen et al. (2016) extended the powering and puzzling framework to include the process of perpetuating, sustaining policy processes of climate adaptation over long periods of time.

However, underdeveloped nations (i.e., Bangladesh, India) will likely face more sociopolitical challenges associated with climate change (Adger et al. 2003) and barriers to adaptation (Biesbroek et al. 2013; Shackleton et al. 2015). An emerging lacuna within climate adaptation literature that utilizes the powering and puzzling framework is that scant attention has been paid to the global South. Specifically, policymaking processes of underdeveloped nations in South Asia (i.e., Bangladesh, India) have substantially reduced capacities to enact sweeping adaptation policies (Vij et al. 2017; Huq et al. 2004; Huq and 
Ayers 2009). Additionally, climate adaptation policy processes of Bangladesh and India must consider the vastly heterogenous populations at larger demographic and geographic scales than have been analyzed in European contexts, which is the reason the powering and puzzling framework was chosen (Conway et al. 2019). This article is a necessary intervention to adaptation literature using the powering and puzzling framework, as it provides vital insights into the aforementioned complexities of climate adaptation policymaking in the context of South Asia.

Climate adaptation is a relatively newer policy domain in India and Bangladesh (Vij et al. 2017). It is evolving through both puzzling and powering phenomena, enacted by policy actors within the political arena. Adaptation policies in both countries are characterized by policymaking processes with insufficient puzzling between different policy actors (Vij et al. 2017, 2018). Further, climate adaptation policymaking processes in South Asia are often top-down and hierarchical, dominated by elites, excluding marginalized groups, line agencies, and civil society (Nagoda and Nightingale 2017; Nightingale 2017; Vij et al. $2018,2019)$. The lack of a broader base of participation and representation of the diverse citizenry is a powering move that circumscribes the puzzling process to interests and ideas of those with decision-making powers. Adaptation policymaking that serves the powerful may not facilitate adaptation for marginalized populations, perhaps even further entrenching their vulnerability to climate change.

Social factors help determine an individual or group's vulnerability to climate-related hazards (Cutter et al. 2000, 2003), posing barriers to adaptation (Biesbroek et al. 2013). This is especially pronounced in the global South (Adger et al. 2003). Policymaking around climate adaptation is often framed by geography and the biophysical vulnerability of place, rather than the social vulnerability of residents (Cutter et al. 2000). Further, adaptation policymaking processes often locate causation of vulnerability in proximate climatic factors (Birkenholtz 2012), wherein vulnerable actors are dependent upon a benevolent state to fulfill its mandate and bring the system back to equilibrium through top-down development programs (Bassett and Fogelman 2013). However, this approach to understanding vulnerability distract from the social and political causation of vulnerability, thereby reinforcing dominant power structures through climate adaptation policy (Ribot 2014; Nagoda and Nightingale 2017; Eriksen et al. 2015; Nightingale 2017). According to Ribot (2010: 49 ), vulnerability “...is produced by on-the-ground social inequality, unequal access to resources, poverty, poor infrastructure, lack of representation and inadequate systems of social security, early warning and planning." Vulnerable actors often lack adaptive capacity, "the ability of systems, institutions, humans and other organisms to adjust to potential damage, to take advantage of opportunities, or to respond to consequences" (IPCC 2014). In human systems, adaptation seeks to moderate or avoid harm or exploit beneficial opportunities. "In some natural systems, human intervention may facilitate adjustment to expected climate and its effects" (IPCC 2014, p. 5). Adaptation can be realized from the local to the global level and be focused on short-term actions or on long-term system transformations (Chhetri et al. 2019).

A vulnerable actor's lack of adaptive capacity is due to their positionality within fundamentally uneven political, economic, and social structures that mediate responses to climatic stressors, not determined by the changing environments in which they live (Taylor 2015; Nightingale 2017; Nagoda and Nightingale 2017; Eriksen et al. 2015; Watts 1983; see Watts and Bohle 1993). Within the adaptation policy domain, problem-framing tends to be dominated by elite groups and solutions offered are often techno-managerial and not contextual (O'Brien et al. 2007; Ribot 2014). These trends are especially prevalent in South Asia (Nightingale 2017). It is within this context that this article seeks to answer 
the following research question: To what effect have powering and puzzling approaches influenced climate change adaptation policy design and implementation processes at the national and sub-national scales in Bangladesh and India? In this article, we argue that adaptation policymaking occurs with a mix of powering and puzzling approaches, is largely top-down, is amenable to techno-managerial solutions, and is not inclusive of marginalized actors.

The article progresses in five further sections. The next section operationalizes the concept of powering and puzzling in the context of climate adaptation. Section 3 elaborates the methods of data collection and the analysis aspects of this article. Section 4 elaborates the results of this research, utilizing the puzzling and powering framework in the context of adaptation policymaking and implementation in Bangladesh and India. Section 5 is the discussion section that builds upon key insights obtained from fieldwork and analysis, putting into conversation this puzzling and powering framework with the broader climate adaptation literature. Section 6 of this article is the conclusion, leaving the reader with a summary of our analysis of empirical findings in an attempt to operationalize the puzzling and powering framework in South Asia.

\section{Powering and puzzling in climate adaptation policy processes: a conceptual framework}

Climate change adaptation requires on-the-ground solutions that are aligned to the perceived problem of climate change among local communities (Stock et al. 2019). If there is a disconnect between the solutions offered by the government and the problem perceived by communities, the adaptation measures will likely fail and actors begin to realize that climate change adaptation is difficult to implement. Thus, it is important to understand the way a problem (i.e., climate change adaptation) is understood and the type of solutions implemented. In this article, the framing of adaptation policymaking is analyzed through powering and puzzling modalities.

As mentioned previously, powering is understood as the ability to exert pressure on and influence other actors to create an acceptance of the problem definitions and certain types of solutions. Powering can involve lobbying to mobilize support for a particular framing, using support for disarming critics and to safeguard the availability of resources for implementing solutions befitting the interests of actors involved. As this research demonstrates below, powering is often used for creating acceptance as well as implementing technocratic and tangible solutions for climate change adaptation. Solutions oriented toward building capacity and intangible outputs are often not prioritized by policymakers (Nagoda and Nightingale 2017; Bassett and Fogelman 2013). As Nightingale (2017) demonstrates, topdown and techno-managerial adaptation policymaking processes can become victim to the domination of influential and powerful figures, producing sites of struggle over authority and recognition for others involved and impacted by adaptation policies. Even climate adaptation policymaking processes that are more participatory can have the effect of reproducing social power that prevents transformational adaptation among marginalized populations included in the process (Nagoda and Nightingale 2017). However, Eriksen et al. (2015) remind us that climate adaptation policy processes can also serve as a domain for actors to contest key components of power: authority, subjectivity, and knowledge. In this 
article, the powering analytical construct is used to interrogate Bangladesh and India's adaptation policy domains.

Puzzling refers to the process of identifying policy-remediable social problems and deliberating a number of possible solutions within spheres of influence. Hoppe (2011) argues that puzzling relates to the process of putting different and contradictory perspectives and visions from actors in a more analytical way of developing policy. Effectively, puzzling is about generating different options for a problem based on different knowledge systems. Policymaking is a collective puzzling exercise of the government on behalf of the society and its related problems (Hall 1993). For example, uncertainty in the adaptation policy domain has not effectively been reduced, despite many commissioned research studies and projects implemented across the globe (Challinor et al. 2014).

Puzzling and powering are not separate (Heclo 1974; Majone 1998). To be effective, puzzling requires powering strategies and vice versa (van der Steen et al. 2016). Puzzling is often a reflexive act, whereas powering tends to be a reactive or proactive implementation of policy. Policy deliberations generally transpire in closed settings, where actors use their power to puzzle and make decisions, interim or final. For example, actors in adaptation policy processes use their authority and control to get access to the setting where adaptation policies are shaped and reshaped. To be able to puzzle, actors need to use their power to change the political discourse in a direction they feel is necessary to establish an advantage.

In certain cases, powering occurs without puzzling. Such scenarios can produce results with only one solution, although possibly enabling openings for decisive and swift action. As Hoppe and Hisschemoller (1995) argue, senior-level bureaucrats often prefer to see problems as a puzzle where there is only one unique solution. This minimizes the uncertainty but restricts the solutions to already existing practices, without allowing collective puzzling within and across institutions and reflexivity among actors to "think outside the box." On the contrary, if puzzling between actors continues without sufficient powering, certain policies and measures are unable to achieve the desired outcome. As a result, these policies can lose importance and get permanently shelved. It is with this conceptual grounding that the climate adaptation policies of Bangladesh and India are analyzed through the powering and puzzling conceptual framework.

\section{Methodology}

\subsection{Research sites}

South Asia is highly vulnerable and possesses a low readiness to respond to climate-related impacts (IPCC, 2007). At present, there is a great variability of vulnerability among and within countries in the region, though Bangladesh is likely the most vulnerable nation (Thornton et al. 2014). Bangladesh is particularly vulnerable to sea and river flooding (Ali 1996). Likewise, floods and droughts affect agricultural productivity in adjacent India (Stock et al. 2019). In addition to country-specific climate vulnerability, Bangladesh and India experience shared climate change impacts due to transboundary natural resources like rivers, watersheds, and mountains (Hijioka et al. 2014). In recent years, policymakers in both countries are puzzling over the phenomenon of climate change and producing several policies that reflect an emergent attempt at responding to climate-related threats. However, 
the social dimensions of climate change are inadequately puzzled over, often reproducing power relations that favor elites. Bangladesh and India's adaptation policy domains were chosen for this research because of political and cultural similarities, geographical proximity, and the authors' previous research commitments to the region.

\subsection{Data collection}

The article uses the interpretive approach and follows a case study method to answer the research question. Our inductive approach was informed by grounded theory (Corbin and Strauss 2008), striving for empirical validity of qualitative data gathered, and ensuring the real world "fit" of our explanations (Sayer 2000). Methods used to research adaptation policy domains are varied. As such, there are no "standardized" methods for approaching adaptation research. (For notable exceptions, see Haddaway et al. 2018; Berrang-Ford et al. 2015.) Data was collected using two strategies - semi-structured interviews (Table 1; $n=91$ ) and discourse analysis of policy documents (Table 2; $n=17$ ). Semi-structured interviews were defensibly chosen as a method for this research to parse out the perception of actors and influence over policymaking processes. Discourse analysis was chosen to examine the specific text of policies and examine policy outcomes represented in texts.

The data for this article was collected between 2014 and 2018. The selection criteria for policy documents chosen for the discourse analysis are the following: (1) binding or influential policy documents related to climate change adaptation; (2) aspirational documents likely to influence future adaptation policymaking. Fieldwork in India was ongoing (2014-2018), conducted throughout Gujarat state and New Delhi. Gujarat was chosen for this study because it was India's first state (also Asia's first) to establish a Climate Change Department within the state government and India's first state to implement a large-scale solar energy plant to mitigate climate change. In Bangladesh, fieldwork was completed during 2016 and 2017 in Dhaka. Spanning urban and rural settings in both countries, we interviewed climate adaptation policy actors at the national and sub-national scales that were involved in the preparation of past and current adaptation policies. Our respondents included serving bureaucrats, consultants directly involved in policy processes, civil society actors, representatives of international development organizations, representatives of NGOs implementing climate projects, and representatives of donor agencies. We also interviewed the staff of various climate adaptation implementation agencies in administrative capitols and rural districts in India and at coastal districts and sub-district scales in Bangladesh (Fig. 1). Interview respondents in both India and Bangladesh also included community members, farmers, and members of village councils on experiences and perceptions of climate change. Interview questions were designed to ascertain power relations, participation, and deliberation within adaptation policy processes and projects among a myriad of actors and stakeholders.

We used a snowball sampling method in policy domains to identify participants in multiple institutions where we did not previously have contacts, thereby ensuring the representation of multiple institutions at various scales of adaptation governance. Respondents were identified on the basis of possessing substantial knowledge on the organizational activities of their respective institution and holding enough expertise to comment as a representative of that institution (DiCicco-Bloom and Crabtree 2006). The duration of each semistructured interview did not exceed one hour, wherein respondents provided a detailed description of their organizational activities in adaptation policy design, management, and implementation. Interviews were conducted in the languages of English, Hindi, Bengali, 


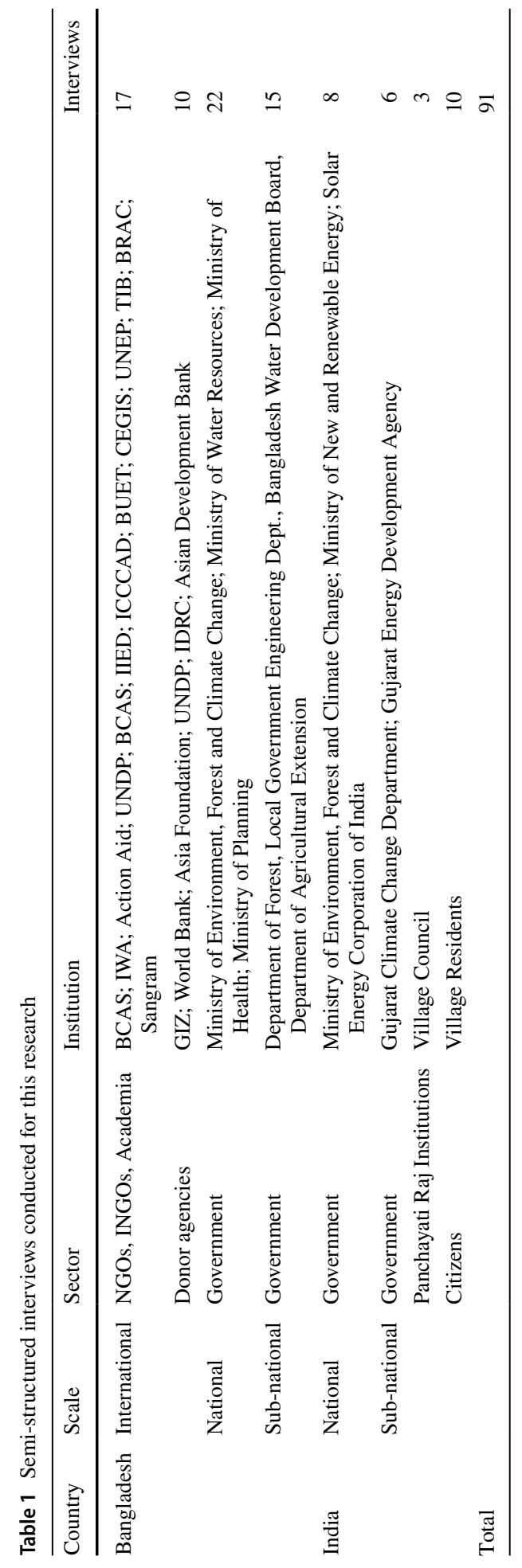




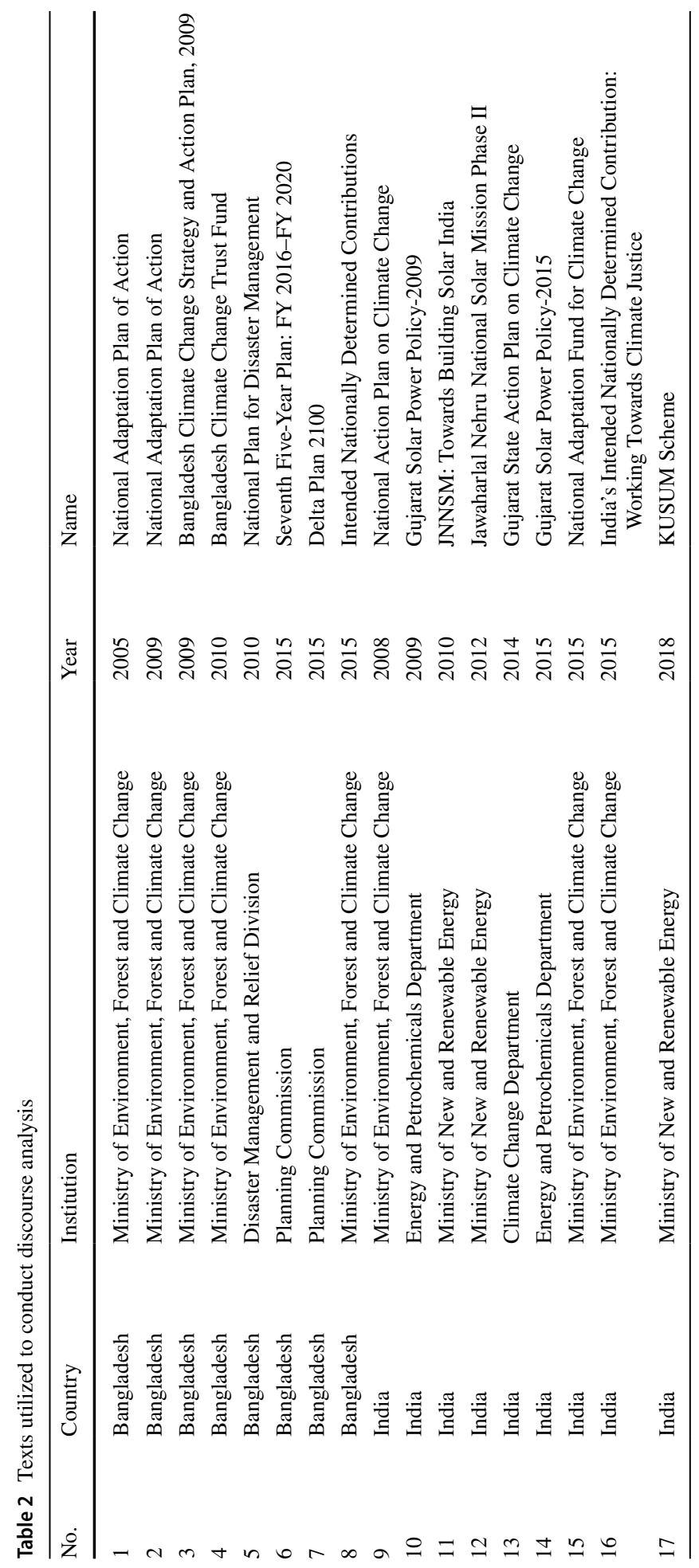




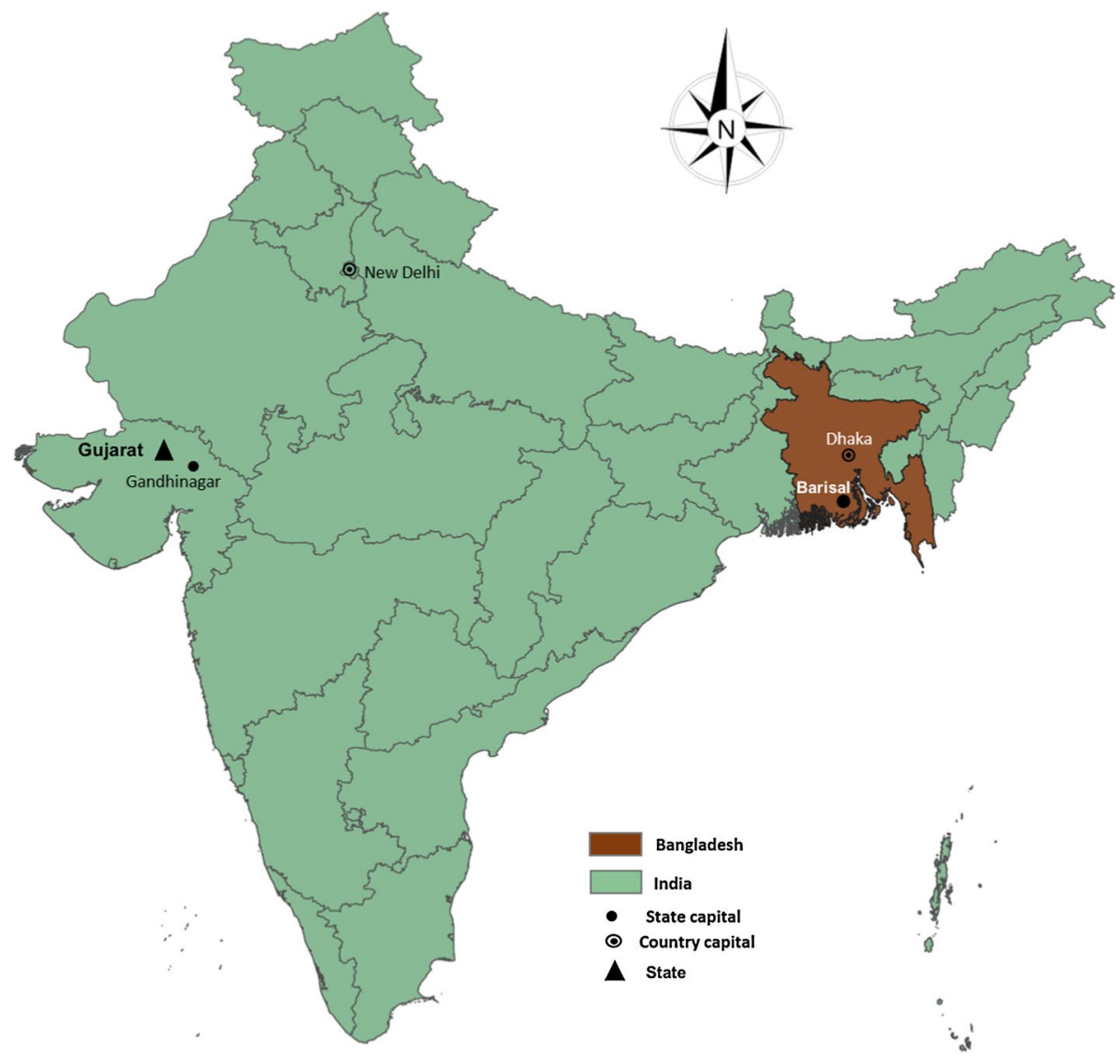

Fig. 1 Locations in Bangladesh and India where fieldwork was conducted

and Gujarati, as per the respondents' fluency. Data quality was ensured by professional translation of interview transcripts, verified by fluent speakers of the language, and standardized analysis techniques for each interview. Interviews were analyzed using qualitative methods, including content and discourse analysis techniques.

\subsection{Data analysis}

Informed by comparative analyses of climate adaptation policymaking (Biesbroek et al. 2010; Vink et al. 2015; Vij et al. 2017, 2018), we analyzed the data to reflect on how powering and puzzling is used for designing and implementation of adaptation strategies. Questions regarding representation and participation of decision-making processes within the policy arena are reflected in the empirical section. To explain powering, we considered aspects such as overpowering of certain actors or ministries, uncoordinated efforts or competing efforts between different "line agencies" (specific ministries or departments). We identified events, through policymakers' interviews or witnessed through participant observation, where: (1) a line agency lost control over designing or implementing policy; (2) a line agency lost funding to a project or a program attached to adaptation. To explain 
puzzling, we scrutinize whether a systematic and inclusive process of deliberation is done before implementing adaptation strategies. Our understanding and assessment of puzzling within the adaptation policy domain are based on the information of actors representing different sectors, variety of adaptation measures, communities that were involved during the process, and how different knowledge systems were used to prepare adaptation measures. For example, we investigate whether adaptation policies consider the context-specific causal structures of vulnerability and intersectional subject positions or merely essentialize populations by the outcome of vulnerability.

\section{Results}

Adaptation policymaking in Bangladesh and India occurs through puzzling and powering approaches. Analyzing data obtained from semi-structured interviews and discourse analysis of policy documents, we present four interrelated claims disaggregated by case study: (1a) climate adaptation policymaking processes in Bangladesh reflect a poor communication and coordination between line agencies, muddling adaptation actions; (1b) elite capture by excluding NGOs and local population from policy deliberations; (2a) climate adaptation policymaking processes in India reflect a lack of deliberation over identifying and differentiating populations vulnerable to climate change; and (2b) lack of deliberation over the political-economic causes of climate change vulnerability, a tactical maneuver to preserve existing power structures.

\subsection{Bangladesh: powering in puzzling}

Since the early 2000s, Bangladesh has been drafting planned adaptation policies, plans, and strategies. Bangladesh already prepared the National Adaptation Plan of Action (2005, updated in 2009), Bangladesh Climate Change Strategy and Action Plan (BCCSAP, 2009), and National Plan for Disaster Management (2010). The government identifies key areas of engagement in the NAPA and charts out a specific action plan in the BCCSAP. Furthermore, in order to implement these plans, Bangladesh created a self-financed Climate Change Trust Fund, allocating more than US\$36 million until 2015, and a Climate Change Resilience Fund with development partners, having allocated approximately US \$187 million until 2014.

Currently, Bangladesh is preparing an updated BCCSAP, NAPA roadmap, and sectoral plans. Policymakers are envisioning a long-term, holistic, and integrated plan-Delta Plan 2100 - a living document to mainstream climate change to national development plans. With these strategies and action plans, Bangladesh is focusing on food and livelihood security (see also Islam 2008), social welfare and protection (see Crow and Sultana 2002), natural resource management (see Meijer and Van Beek 2011), research and knowledge management, climate resilient infrastructure, and institutional capacity building. To ensure economic growth and development, Bangladesh specifies short-to-medium-term adaptation plans addressing all major development sectors and includes those in the Five-Year Plans and Annual Development Plans. In the seventh Five-Year Plan (2016-2020), Bangladesh dedicates a full chapter to climate change and sustainable development addressing the potential climate change impacts and strategies to deal with them. Furthermore, the mid-implementation review of the sixth Five-Year Plan found that the government took the 
initiative to review and redraft the sectoral legislations according to different international protocols on the environment.

The participation of different actors in the policy processes facilitates the puzzling over adaptation policies, but at the same time it sets a common ground that is conducive for the exercise of power. This exercise of power in adaptation processes by different actors in Bangladesh is visible through policy and techno-social contestations. Although the climate policy paradigm in Bangladesh has been shifted toward mainstreaming climate adaptation (Ayers 2011; Ayers et al. 2014; Vij et al. 2018), the majority of organizations under Bangladesh's government ministries do not address climate change explicitly in their mandates. Policy contestation arises with more emphasis on their sectoral policies rather than on the adaptation plan and strategies. For example, the Ministry of Environment, Forest and Climate Change emphasizes more on its sectoral policy and focuses on afforestation in newly formed coastal islands, while the adaptation action plan on creating a contiguous green belt along the coast is largely ignored. Respondents mentioned that various actors within these organizations understand and acknowledge the significance of adaptation plans and strategies, yet it has not been reflected in their operational mandates, mostly due to resource unavailability and lack of coordination. For example, an official at the Bangladesh Water Development Board admitted: "We know that large tidal fluctuations in the coastal areas can be aggravated by increasing sea level rise and our embankments should be heightened up to protect our coastal lands. But we cannot afford to increase the height of the embankment beyond a certain limit as we are a small, developing country with limited financial and physical resources. As a result, in the coastal areas, we primarily focus on maintaining the existing embankments" (personal communication, 12 June 2017).

Despite having enveloping climate adaptation plans and strategies, techno-social contestation arises when Bangladesh concentrates more on technical solutions and less on social welfare or protection measures, which represents a form of powering. For instance, under the Coastal Climate Resilient Infrastructure Project, Bangladesh constructed disaster shelters in many areas in accordance with adaptation plans and strategies. However, despite having improvised a warning and evacuation system, many flood-affected households are reluctant to seek refuge in these shelters because of a mistrust in warning signs, religious conservativeness, fear of household theft, and obliviousness to the impacts of previous events (Alam and Collins 2010; Garai 2017; Ishtiaque et al. 2017). During cyclone Mora, for instance, the Bangladesh Meteorological Department raised the warning signal to 8 (great danger) in the central coastal areas in fear of strong winds and a storm surge. Nevertheless, the cyclone made landfall in southeastern Bangladesh, leaving the central coastal part unaffected. One representative of a local NGO candidly stated, "the government wanted us to help evacuate the vulnerable people under the warning signal 8, but they laughed at the evacuation process indicating the clear and sunny sky" (personal communication, 9 June 2017).

In many instances, local-level social agencies place emphasis upon short-term disaster preparedness or recovery initiatives at the expense of longer-term adaptation plans. This is particularly evident in the case of local NGOs. The Bangladesh government encourages NGOs to play active roles in enhancing local adaptive capacity and thus channels $10 \%$ of the Climate Change Resilience Fund to them (GED 2015). However, apart from some large NGOs, most of them are accused of concentrating more on disaster recovery, post-disaster relief and aid (Khan and Rahman 2007; Islam and Walkerden 2015). In this way, NGOs are sidelined from the adaptation implementation processes.

The above-mentioned climate adaptation policy efforts are coordinated by different donor and bilateral agencies attached to respective ministries (Rahman and Tosun 2018). 
For example, NAPA was coordinated by the United Nations Development Programme and BCCSAP was coordinated by the International Union for Conservation of Nature, among other agencies. More than 39 ministries, along with their sub-departments and autonomous organizations, and at least 10 international development or donor agencies, were involved in formulating and implementing adaptation strategies and plans in Bangladesh (MOEFCC 2009). However, the process of collective puzzling is missing and powering by a few actors remains dominant in adaptation policymaking, corroborating Nightingale's (2017) central thesis. These multiple strategies and plans are creating a new layer of power interplays between ministries and supporting agencies, hampering a required coordinated effort to reduce climate change impacts. For instance, the Ministry of Environment, Forest and Climate Change is intended to be at the forefront of coordinating all climate-related activities. Yet, their structural debility, duality in mandate, and lack of resources allowed the infrastructure and social protection-related ministries and agencies to become more independently dominant in the adaptation policy network (O'Donnell et al. 2013). Like Bangladesh, India also faces many institutional constraints to successful powering and puzzling around climate change adaptation.

\subsection{India: powering without puzzling}

Impacts of anthropogenic climate change remain a puzzling realm (Dessai et al. 2007), especially for policymakers in India. On June 30, 2008, the Government of India released the National Action Plan on Climate Change (NAPCC). Each of the eight national missions deals with aspects of climate adaptation (Government of India 2008; Vij et al. 2017). However, the powering aspect of the NAPCC lies in its lack of puzzling around the question of differentiated vulnerability by axes of social difference and apolitical vulnerability discourses, which is a crucial component of effective and equitable adaptation policy. The NAPCC text identifies vulnerability via undifferentiated heavily populated regions that are vulnerable to sea-level rise, drought, and crop failure due to increased aridity (Government of India 2008: 16). By decontextualizing vulnerability from other forms of social difference (i.e., gender, caste, class) (see Djoudi et al. 2016; Sultana 2014; Carr and Thompson 2014; Nightingale 2011), the Government of India reserves the space for planned technical adaptation interventions (i.e., drought-proofing, rainwater harvesting, groundwater and irrigation management, crop insurance schemes) that maintain the political economic status quo.

Apropos to this discussion, one scientist directly involved in policymaking at Government of India's Ministry of Environment, Forestry and Climate Change in New Delhi candidly admitted his lack of nuanced understanding of vulnerability: "There are many types of vulnerability. Who is vulnerable to what? That phenomenon, we do not know. In this uncertainty, we are trying to understand vulnerability. People are vulnerable to a lot of things. We have 101 definitions of vulnerability, but we don't know how to measure it. Please tell me, how do you measure vulnerability? You see, it is very difficult to measure these things. We do not know how vulnerable we are" (personal communication, 20 July 2018). Likewise, another scientist at the Ministry struggled with identifying specific populations disproportionately vulnerable to climate-related impacts: "Vulnerability is very tough to answer. In India, our geologic and demographic features are so varied. You cannot say that one population is vulnerable or another population is vulnerable" (personal communication, 20 July 2018). Similarly, a respondent at the Solar Energy Corporation of India echoed these same ambiguous sentiments: "For climate change, every Indian is 
vulnerable for that. Really everyone is experiencing the bad effects of climate change" (personal communication, 16 July 2018).

Ostensibly, the adaptation policy domain at the national scale empowers states to focus on development imperatives at sub-national scales (Atteridge et al. 2012; Jorgensen et al. 2015; Remling and Persson 2015; Sherman et al. 2016), though often circumscribes their space for innovation (Jogesh and Dubash 2015). By 2009, each of the 29 Indian states and 7 union territories was required to draft a State Action Plan for Climate Change (SAPCC), implementing a common national framework elaborated by the Ministry of Environment, Forestry and Climate Change that is tailored to each state's unique vulnerabilities (Government of India 2008). Presently, 32 SAPCC's have been approved by the Government of India's National Steering Committee on Climate Change (MoEF 2017). Sub-national climate policies retain similar patterns of powering and dearth of vulnerability puzzling, both within decision-making and implementation of adaptation policies. In Rajasthan, state-led adaptation programs (planned) draw upon farmers' local ecological knowledge of climatic variability (including their autonomous adaptations) to lure them into capital-intensive groundwater irrigation projects that consolidate decision-making power and groundwater management away from the farmers (Birkenholtz 2014).

Gujarat's SAPCC identifies vulnerable socioeconomic systems, commodity export crops, indigenous tree species, and specific ecosystems (Government of Gujarat 2014; see Jorgensen et al. 2015). Another section identifies a range of factors which may interact with various determinants of health outcomes but fails to identify specific negative health outcomes nor their cause (Government of Gujarat 2014: 120). In a later section, women and children are identified as vulnerable because of their social roles, but the population identified is not nuanced, nor contextualized within a political economy or among other intersectional subjectivities. Likewise, the Government of Gujarat's SAPCC identifies tribal and indigenous communities, coastal communities, urban poor, marginal and landless farmers/ pastoralists as vulnerable without cause or nuance, thereby representing seemingly homogenous victims whose precarity becomes naturalized (Government of Gujarat 2014).

Climate adaptation policymakers in Gujarat are also struggling to identify which populations are disproportionately vulnerable to climate change. A technical advisor at the Gujarat Climate Change Department stated, "I think almost 50\% of the state population is vulnerable. Vulnerability is very high because of the huge population of the state" (personal communication, 23 July 2018). Without identifying targeted groups but utilizing sophisticated and specific climate science syntax, this same bureaucrat went on to declare the positive benefits of his department's adaptation projects: "We've developed their adaptive capabilities. Through socioeconomic modes, they get mainstreamed. That's how they reduce their vulnerability. We keep them informed through various ways and means and newspapers and radios and TV advertisements and all these things" (personal communication, 23 July 2018). However, one smallholding farmer interviewed from the state insisted that information was not enough. "The government tells us what to grow because of the changing climate. But I need more water in the summer to do that" (personal communication, 30 December 2014). An upper-caste farmer from the same village summed up his assessment of adaptation assistance: "If there's a major climate related problem in the entire country, the government will step in and help. But not for smaller isolated situations. If there's an election coming up, they will do more" (personal communication, 15 January 2015). Despite the lack of planned adaptation initiatives in the village, many of these farmers are implementing autonomous adaptation initiatives, including livelihood diversification and resource sharing (Stock et al. 2019). Overwhelmingly, assistance (i.e., financial, 
technological) and access, not information, was the principal limiting factor to adaptation among community members interviewed.

As seen in the NAPCC and Gujarat's SAPCC, similar patterns of powering and puzzling are evident in the Government of India's Nationally Determined Contributions (NDC) to fulfill its greenhouse gas reduction obligations under the 2015 UNFCCC Paris Agreement (Government of India 2015). India's NDC has identified the planning and implementation of actions to enhance climate resilience and reduce vulnerability to climate change as a priority area for policymaking, yet still fails to identify both a cause and population relating to its discourse of vulnerability (Government of India 2015: 30). The document simply identifies vulnerable sectors of the economy and segments of the society, again without adequately puzzling over the question of vulnerability to help facilitate adaptation measures for those who need it most (Government of India 2015: 30). Moreover, India's NDC refers to the totality of SAPCC's and the NAPCC as a holistic disaster risk reduction and response apparatus, yet it remains unclear as to how these documents will transform the political economy to facilitate the emancipation of populations whose intersectional differences and positionality mediate their vulnerability. The NDC indicates the Government of India's intention to establish a National Adaptation Fund ( US \$55.6 million) that will fund new adaptation initiatives identified, such as the Paramparagat Krishi Vikas Yojana scheme (organic farming promotion), Pradhan Mantri Krishi Sinchayee Yojana (efficient irrigation promotion), Neeranchal (watershed development), and the Give it up campaign (cooking gas subsidy transfer to poor). Each of these schemes facilitate climate adaptation and protects livelihoods. However, India's NDC suffers from the same dearth of puzzling over powering as the NAPCC and SAPCCs, revealed by its lack of specificity of which populations remain vulnerable to climate change and why (despite claims in the document's title of working towards climate justice).

\section{Discussion}

This research demonstrates the propensity of climate adaptation policymaking to be topdown, seeking techno-managerial solutions, and not inclusive of marginalized actors. These policy insights from Bangladesh and India undergird the relevancy of this conceptual framework to analyze adaptation policymaking processes. In the following paragraphs, we reflect on the ways Bangladesh and India are puzzling and powering in adaptation policymaking processes.

Bangladesh has been successful in puzzling the problem of climate change by formulating plans and policies for the key sectors such as water, agriculture, health, and education. However, power interplays at different levels of governance undermine the success in puzzling. Lack of participation of vulnerable local groups, who experience the most severe climate impacts, in the policymaking process and the inadequate focus on the underlying drivers of climate vulnerability impair the puzzling process. In the implementation process, power asymmetries among actors result in a decreased focus on social aspects, attention limited to short-term impacts, and inadequate coordinated efforts.

While exercising the decision-making powers that produce policy measures, Bangladesh is ostensibly successful in puzzling over adaptation policies and in framing them in broader development contexts. However, we found that while puzzling the climate change problem, the Bangladesh government has taken a sectoral top-down approach and disregarded the underlying drivers of vulnerability. Participation of local people in the puzzling 
process is insufficient and represents a power asymmetry among actors. The government agencies exclude marginalized populations who are likely vulnerable to climate-related stressors from the decision-making process. Also, climate adaptation is often confused with disaster risk reduction; as such, its focus relies too much on exposure or short-term impacts. Such muddling of adaptation and disaster risk reduction could undermine the success in puzzling.

Our analysis indicates that social aspects of the adaptation policy domain do not get the similar emphasis as technical aspects, representing power asymmetries. The social agencies are oftentimes confined by resource limitations, limited innovations, and episodic actions during emergencies. Most of the government organizations do not collaborate or network with civil society, which is unfortunate because certain large NGOs could contribute significantly to vulnerability reduction. In sum, failure to incorporate the expertise of social agencies and excluding NGOs from the adaptation decision-making process is a representation of power dynamics at the sub-national scale. Such power interplays indicate a lack of puzzling at the local scale. In this way, national-scale puzzling within policymaking may be impaired by local-scale power interplays.

Bangladesh's top-down, hierarchical approach of governance hinders the adaptation policy implementation process. While at the local scale, the coordination and communication among agencies implementing adaptation plans are attributed by frequent informal interactions, they do not have enough authority or power to influence the overall implementation processes occurring at higher scales of governance, a representation of power asymmetry that further substantiates Nightingale's (2017) case study on elite capture in climate adaptation policy. The ministries and their national-scale supporting agencies are responsible for planning and directing the adaptation strategies. Contrary to the local scale, these agencies mostly act alone through their associated organizations with little external coordination. This constellation of donor and government agencies manifests an environment of confusion and competition for implementing the adaptation plan and strategies. Certain actors, such as the Planning Commission under the Ministry of Planning, attempt to connect the stakeholders together. Yet poor inter-ministerial coordination becomes the largest hurdle in the implementation process of adaptation policy because most often these ministries individually prepare adaptation plans with no collaboration with other ministries working in the same geographic space. For sustainable climate adaptation policy efforts, Bangladesh must resolve the question, who coordinates policy efforts, who converges them, and who integrates them? If adaptation policy efforts remain fragmented, adaptation will have more limitations than successes.

In sum, Bangladesh's climate adaptation policy domain will require a more balanced puzzling and powering approach at different levels of governance. Bangladesh needs more puzzling at the local level to succeed at developing an overarching institutional mechanism to integrate and implement the aforementioned adaptation policies and to ensure the success of adaptation across scales. The current impact-based top-down sectoral approach requires more focus on local livelihoods and increased participation of stakeholders in decision-making processes. Furthermore, sectoral policies of line ministries need to be aligned with climate adaptation policies. Likewise, adaptation plans and strategies need to be reflected in the mandates (rules of business) of their supporting organizations. Bangladesh also needs to establish an inter-ministerial coordinating agency and empower it accordingly to dovetail the efforts of the ministries, avoid maladaptation, and increase efficiency to use limited adaptation funds. Otherwise, such fragmented adaptation policy efforts will become the principal problem to puzzle over in the policy domain and thereby remain powerless to adapt. 
At India's national scale of climate change adaptation policymaking, it is clear from the aforementioned examples that policymakers' lack of conceptual clarity on vulnerability directly translates into vague adaptation policies that do not enable transformational adaptation. The powering actions implement adaptation plans that focus on "outcome vulnerability," as opposed to causal structures, and too generic to respond to local variations in vulnerability. These discourses reflect a powering approach of hiding behind the poor, also used by national-scale policymakers to gain power during international negotiations (Chakravarty and Ramana 2012). This powering move reinforces the legitimacy and authority of state actors via dominant discourses that perpetuate "common sense" yet apolitical narratives of vulnerability, simultaneously silencing alternative vulnerability discourses that root causality within the political economy (see Rose 2001; Lukes 2005). Apolitical vulnerability discourses enable decision-making powers within adaptation policy domains, powers that circumscribe the extent of puzzling. Such discursive silences (Rose 2001) around vulnerability circumscribe the authority, subjectivity, and knowledge that comprise climate adaptation policymaking. In spite of India's genealogy of climate policy targeting adaptation, the question remains: adaptation for whom? The principal policy focus for India has been and will likely continue to be top-down, techno-managerial, and largely mitigation-focused climate change policy (see Government of India 2008; Modi 2011; Government of India 2015) and disaster response (Ramanujam et al. 2012). Climate adaptation policies are largely a platform for powering by elites (see Nightingale 2017).

Policy documents that identify potentially vulnerable populations but neglect to locate vulnerability within social and political causes are also power interplays by policymakers in Gujarat not wishing to address, nor puzzle over, sub-national inequalities. The state's reluctance to embrace transformational adaptation by proactively addressing power asymmetries is unsurprising. In recent decades, the state has become synonymous with the rise in Hindu nationalism (Hindutva) (Guha 2013; Bhatt 2013), epitomized by the dominant far-right Bharatiya Janata Party (BJP) and the rise of Narendra Modi (former Chief Minister of Gujarat, current Prime Minister of India). Modi's India (like Modi's Gujarat) is characterized by neoliberal economic policy, dismantling of social welfare schemes, and discrimination of ethnic and religious minorities (Chatterji et al. 2019). Although Modi received much acclaim for founding Asia's first Climate Change Department (in Gujarat), it is increasingly clear that many elite nationalists like Narendra Modi are unconcerned about climate change vulnerability or lack of adaptive capacity among marginalized groups.

The limited success in puzzling over power asymmetries in climate change adaptation is also marred through the caste-based inequalities in agrarian transformation (Stock and Birkenholtz 2019; Gidwani 2000; 2008), gender discrimination in community-based forestry institutions (Agarwal 2010), and religious-based exclusion of disaster relief (Mehta 2009). Despite the aforementioned power imbalances and policy injustices in rural Gujarat, farmers are already adapting their livelihoods to climatic variability (Stock et al. 2019; Jain et al. 2015). Many of these farmers are not included in puzzling processes at the subnational scale; however, they are indeed puzzling over autonomous adaptation in the context of their own livelihoods and at the scale of the village (Stock et al. 2019). Although not bottom-up implementation of adaptation policy, autonomous adaptations by these farmers challenge the legitimacy of top-down adaptation policy. Given that the state of Gujarat is the current Prime Minister's home state, it is unsurprising that its SAPCC is closely aligned with the Government of India's approach to adaptation and vulnerability. Gujarat's SAPCC is an example of how questions of powering are not sufficiently puzzled over in policy documents regarding environment and development. 
Although not explicitly an adaptation policy, the much acclaimed summer 2018 rollout of the Government of India's new KUSUM (Kisan Urja Suraksha Evam Utthaan Mahaabhiyan) scheme to provide 2.75 million solar-powered water pumps for irrigation (synergistically contributing to both climate change adaptation and mitigation; see Government of India 2018) did not include any public consultation process with farmers prior to implementation (personal communication, 31 July 2018). KUSUM is yet another example of climate-related policymaking in India that perpetuates the lack of participation and representation by not collectively puzzling with potentially vulnerable populations, bearing in mind that representation is "not a panacea" (Ribot and Larsen 2005) and participatory approaches can have "tyrannous" results (Cook and Kothari 2001).

The unprecedented monsoon flooding of 2017 and subsequent deaths of largely poor and rural people (Safi 2017) are tragic examples of adaptation policy that failed to adequately puzzle over the social and political causes of climate vulnerability (Taylor 2015; O'Keefe et al. 1976; Watts 1983; Watts and Bohle 1993). India's increasing importance in international-scale climate negotiations already includes political discourses around vulnerability that are pro-poor (Jaeger and Michaelowa 2016; Chakravarty and Ramana 2012). Working towards climate justice within India necessitates puzzling over adaptation at the national and sub-national scales that include clearly articulated pro-poor schemes (Dubash 2012) to improve access to entitlements and processes that enshrine empowerment for vulnerable populations. Further, India's national-scale climate adaptation policy domain needs powering by the poor via increased participation by vulnerable populations and local communities (Rastogi et al. 2014; Phadke 2005; see Nagoda and Nightingale (2017) for a critique of participatory adaptation approaches in Nepal). Apart from the above-mentioned specific insights on Bangladesh and India, two broader insights on power and puzzling modalities are discussed below.

First, powering in climate adaptation often comes from policies that either fail to include puzzling as an approach of deliberation or failure to contextualize the social and political causes of vulnerability (i.e., access to entitlements, social welfare schemes; see Rai and Smucker 2016), thus reinforcing asymmetrical power relations between differently situated actors at multiple scales of governance (Nagoda and Nightingale 2017; Eriksen et al. 2015; Vij et al. 2018). To implement effective adaptation measures, the policy domains in Bangladesh and India must both power and puzzle. Though widely seen as leaders in the South Asia region for climate change policy, it is evident that Bangladesh and India both struggle with asymmetrical power relations and inadequate puzzling in their respective adaptation policy domains which prevents these policies from facilitating transformational adaptation (see Eriksen et al. 2015).

Second, the conceptual grounding of powering and puzzling generates insights into the policymaking and implementation processes. Such refined analyses have the potential to improve adaptation policies in South Asia, a region particularly susceptible to negative climate-related impacts. The powering and puzzling framework can be used beyond just adaptation policy domains in South Asia, potentially providing vital insights into mitigation and development policies elsewhere (see Newton et al. 2015). 


\section{Conclusion}

The objective of this research is to understand how different approaches to climate change adaptation policymaking influence policy design and implementation processes in South Asia. To do so, we utilize a powering and puzzling framework to assess adaptation policy domains. In India and Bangladesh, we conclude that adaptation policy documents have been designed by the way of puzzling by policymakers, donors, and other influential actors in a top-down fashion at different scales. Autonomous and community-based adaptation efforts are also occurring in the region (Conway et al. 2019; Stock et al. 2019; Mathew, Truck and Henderson-Sellers, 2012; see Huq and Reid 2007), but not the focus of this research. Likewise, we conclude that the policy documents analyzed (planned adaptation initiatives) represent a powerful push toward techno-managerial solutions that perpetuate power asymmetries. This research provides a necessary intervention in the climate adaptation literature that utilizes the powering and puzzling framework to analyze policymaking processes, which insufficiently focuses on the global South. Our findings provide vital insights into the complex adaptation policy domains and vastly heterogenous socioeconomic context of Bangladesh and India.

In Bangladesh, national-scale adaptation policy processes suffer from fragmented implementation, dual or conflicting mandates, and lack of coordination. Though policy integration at the sub-national and national scales is more streamlined in India, elites dominate the adaptation policy domain. Climate adaptation policymaking in India includes inadequate puzzling over the causes of vulnerability to necessitate techno-managerial solutions that do not remediate the social and political causes of vulnerability. India is neglecting to locate vulnerability within sociopolitical causes; policymakers are seemingly unwilling to address sub-national inequalities around caste and religious-based discrimination and lack of resource access. Moving forward, both countries should strive to make adaptation policies that facilitate participation of marginalized populations and represent their anxieties and aspirations. Perhaps, their participation is the missing piece of the climate adaptation policy puzzle, a move that may lead to empowerment.

Acknowledgements Fieldwork in Bangladesh was carried out by the Himalayan Adaptation, Water and Resilience (HI-AWARE) consortium under the Collaborative Adaptation Research Initiative in Africa and Asia (CARIAA). Fieldwork in Bangladesh was supported by the UK Department for International Development (DFID, UK), the International Development Research Centre (IDRC, Ottawa), and the Mathew G. Bailey Fellowship from Arizona State University. Fieldwork in India was conducted with administrative support from the Indian Institute of Management Ahmedabad's (IIM-A) Public Systems Group and financial support from the Fulbright-Hays Doctoral Dissertation Research Abroad fellowship (P022A170064; US Department of Education), the Fulbright-Nehru Research Award (US Department of State-IIE), the Critical Language Enhancement Award (American Institute of Indian Studies), the Due and Ferber International Award and the Barbara Yates International Award from the Women and Gender in Global Perspectives (WGGP) program at the University of Illinois at Urbana-Champaign. Our immense gratitude goes to Trevor Birkenholtz, Robbert Biesbroek, Netra Chhetri, Amit Garg, Sheikh Mofizul Islam (Director, National Institute of Local Government), Moktar Hossain (Additional Deputy Commissioner, Patuakhali), Dr. Md. Bashirul Alam (Deputy Commissioner, Barguna), Shamim Chowdhury, Tasnuba Jerin, Shilpa Jhobalia, Shyan, Lakshay, Raysha and numerous respondents from both countries.

Open Access This article is licensed under a Creative Commons Attribution 4.0 International License, which permits use, sharing, adaptation, distribution and reproduction in any medium or format, as long as you give appropriate credit to the original author(s) and the source, provide a link to the Creative Commons licence, and indicate if changes were made. The images or other third party material in this article are included in the article's Creative Commons licence, unless indicated otherwise in a credit line to the material. If material is not included in the article's Creative Commons licence and your intended use is not 
permitted by statutory regulation or exceeds the permitted use, you will need to obtain permission directly from the copyright holder. To view a copy of this licence, visit http://creativecommons.org/licenses/by/4.0/.

\section{References}

Adger, W. N., Huq, S., Brown, K., Conway, D., \& Hulme, M. (2003). Adaptation to climate change in the developing world. Progress in development studies, 3(3), 179-195.

Agarwal, B. (2010). Gender and green governance: The political economy of women's presence within and beyond forestry. New Delhi: Oxford University Press.

Alam, E., \& Collins, A. E. (2010). Cyclone disaster vulnerability and response experiences in coastal Bangladesh. Disasters, 34(4), 931-954.

Ali, A. (1996). Vulnerability of Bangladesh to climate change and sea level rise through tropical cyclones and storm surges. Climate change vulnerability and adaptation in Asia and the Pacific (pp. 171-179). Dordrecht: Springer.

Atteridge, A., Shrivastava, M. K., Pahuja, N., \& Upadhyay, H. (2012). Climate policy in India: What shapes international, national and state policy? Ambio, 41(Suppl 1), 68. https://doi.org/10.1007/ s13280-011-0242-5.

Ayers, J. (2011). Resolving the adaptation paradox: Exploring the potential for deliberative adaptation policy-making in Bangladesh. Global Environmental Politics, 11(1), 62.

Ayers, J. M., \& Huq, S. (2009). The value of linking mitigation and adaptation: A case study of Bangladesh. Environmental Management, 43(5), 753-764.

Ayers, J. M., Huq, S., Faisal, A. M., \& Hussain, S. T. (2014). Mainstreaming climate change adaptation into development: A case study of Bangladesh. Wiley Interdisciplinary Reviews: Climate Change, 5(1), 37-51. https://doi.org/10.1002/wcc.226.

Bassett, T., \& Fogelman, C. (2013). Déjà vu or something new? The adaptation concept in the climate change literature. Geoforum, 48, 42-53.

Berrang-Ford Pearce, T., \& Ford, J. D. (2015). Systematic review approaches for climate change adaptation research. Regional Environmental Change, 15(5), 755-769.

Bhatt, C. (2013). Democracy and Hindu nationalism. In J. Anderson (Ed.), Religion, democracy and democratization. New York: Routledge.

Biesbroek, G. R., Klostermann, J. E., Termeer, C. J., \& Kabat, P. (2013). On the nature of barriers to climate change adaptation. Regional Environmental Change, 13(5), 1119-1129.

Biesbroek, G. R., Swart, R. J., Carter, T. R., Cowan, C., Henrichs, T., Mela, H., et al. (2010). Europe adapts to climate change: Comparing national adaptation strategies. Global Environmental Change, 20(3), 440-450.

Birkenholtz, T. (2012). Network political ecology method and theory in climate change vulnerability and adaptation research. Progress in Human Geography, 36(3), 295-315.

Birkenholtz, T. (2014). Knowing climate change: Local social institutions and adaptation in Indian groundwater irrigation. The Professional Geographer, 66(3), 354-362.

Carr, E. R., \& Thompson, M. C. (2014). Gender and climate change adaptation in agrarian settings: Current thinking, new directions, and research frontiers. Geography Compass, 8(3), 182-197.

Chakravarty, S., \& Ramana, M. V. (2012). The hiding behind the poor debate: A synthetic overview. In Navroz Dubash (Ed.), Handbook of climate change and India (pp. 218-229). New York: Earthscan.

Challinor, A. J., Watson, J., Lobell, D. B., Howden, S. M., Smith, D. R., \& Chhetri, N. (2014). A metaanalysis of crop yield under climate change and adaptation. Nature Climate Change, 4(4), 287.

Chatterji, A. P., Hansen, T. B., \& Jaffrelot, C. (2019). Majoritarian state: How Hindu nationalism is changing India. Oxford, UK: Oxford University Press.

Chhetri, N., Stuhlmacher, M., \& Ishtiaque, A. (2019). Nested pathways to adaptation. Environmental Research Communications, 1(1), 015001.

Conway, D., Nicholls, R. J., Brown, S., Tebboth, M. G., Adger, W. N., Ahmad, B., et al. (2019). The need for bottom-up assessments of climate risks and adaptation in climate-sensitive regions. Nature Climate Change, 9(7), 503-511.

Cook, B., \& Kothari, U. (2001). Participation-the new tyranny? (4th ed.). London: Zed Press.

Corbin, J., \& Strauss, A. L. (2008). Basics of qualitative research: Grounded Theory procedures and techniques (3rd ed.). London: Sage. 
Crow, B., \& Sultana, F. (2002). Gender, class and access to water: Three cases in a poor and crowded delta. Society and Natural Resources, 15(8), 709-724.

Culpepper, P. D. (2002). Powering, puzzling, and 'pacting': The informational logic of negotiated reforms. Journal of European Public Policy, 9, 774-790. https://doi.org/10.1080/1350176021 0162357.

Cutter, S. L., Boruff, B. J., \& Shirley, W. L. (2003). Social vulnerability to environmental hazards. Social Science Quarterly, 84(1), 242-261.

Cutter, S., Mitchell, J., \& Scott, M. (2000). Revealing the vulnerability of people and places: A case study of Georgetown County, South Carolina. Annals of the Association of American Geographers, 90, 713-737. https://doi.org/10.1111/0004-5608.00219.

Dessai, S., O’Brien, K., \& Hulme, M. (2007). On uncertainty and climate change. Global Environmental Change-Human and Policy Dimensions, 17(1), 1-3.

DiCicco-Bloom, B., \& Crabtree, B. F. (2006). The qualitative research interview. Medical Education, 40(4), 314-321.

Djoudi, H., Locatelli, B., Vaast, C., Asher, K., Brockhaus, M., \& Sijapati, B. B. (2016). Beyond dichotomies: Gender and intersecting inequalities in climate change studies. Ambio A Journal of the Human Environment, 45(3), S248-S262. https://doi.org/10.1007/s13280-016-0825-2.

Dubash, N. K. (2012). Climate politics in India. In Navroz Dubash (Ed.), Handbook of climate change and India (pp. 197-207). New York: Earthscan.

Eriksen, S. H., Nightingale, A. J., \& Eakin, H. (2015). Reframing adaptation: The political nature of climate change adaptation. Global Environmental Change, 35, 523-533.

Garai, J. (2017). Qualitative analysis of coping strategies of cyclone disaster in coastal area of Bangladesh. Natural Hazards, 85(1), 425-435.

GED (General Economic Division) (2015) Seventh Five Year Plan: FY 2016-FY2020. Dhaka: Planning Commission, Government, of the People's Republic, of Bangladesh.

Gidwani, V. (2000). The quest for distinction: A reappraisal of the rural labor process in Kheda District (Gujarat), India. Economic Geography, 76(2), 145-168.

Gidwani, V. (2008). Capital, interrupted: Agrarian development and the politics of work in India. Minneapolis: University of Minnesota Press.

Government of Gujarat, (2014). State action plan on climate change. Gandhinagar, India: Climate Change Department. Retrieved 3 August 2017.

Government of India, (2008). National action plan on climate change. New Delhi, India: Prime Minister's Council on Climate Change. Retrieved 2 August 2017.

Government of India, (2015). India's Intended Nationally Determined Contribution: Working towards climate justice. New Delhi: Government of India. Retrieved 7 August 2017.

Government of India, (2018). KUSUM scheme. New Delhi: Ministry of New and Renewable Energy. Retrieved 1 August 2018, from http://pib.nic.in/PressReleaseIframePage.aspx?PRID=1524553.

Guha, S. (2013). Beyond caste: Identity and power in South Asia, past and present. Boston: Brill.

Haddaway, N. R., Macura, B., Whaley, P., \& Pullin, A. S. (2018). ROSES RepOrting standards for Systematic Evidence Syntheses: pro forma, flow-diagram and descriptive summary of the plan and conduct of environmental systematic reviews and systematic maps. Environmental Evidence, 7(7), 1-8.

Hall, P. A. (1993). Policy paradigms, social learning, and the state: The case of economic policymaking in Britain. Comparative Politics, 1, 275-296.

Heclo, H. (1974). Modern social politics in Britain and Sweden: From relief to income maintenance. New Haven: Yale University Press.

Hijioka, Y., Lin, E., Pereira, J. J., Corlett, R. T., Cui, X., Insarov, G. E., et al. (2014). Asia. Climate Change 2014: Impacts, Adaptation, and Vulnerability. Part B: Regional Aspects. Contribution of Working Group II to the Fifth Assessment Report of the Intergovernmental Panel on Climate Change. In V. R. Barros, C. B. Field, D. J. Dokke, M. D. Mastrandrea, K. J. Mach, T. E. Bilir, M. Chatterjee, K. L. Ebi, Y. O. Estrada, R. C. Genova, \& B. Girma (Eds.), Climate change 2014: impacts, adaptation, and vulnerability-Part B: regional aspects-Contribution of Working Group II to the Fifth Assessment Report of the Intergovernmental Panel on Climate Change. Cambridge: Cambridge University Press.

Hoppe, R. (2010). Lost in translation? A boundary work perspective on making climate change governable. In P. Driessen, P. Leroy, \& W. van Viersen (Eds.), From climate change to social change: perspectives on science-policy interactions (pp. 109-130). Utrecht, Netherlands: International Books.

Hoppe, R. (2011). The governance of problems: Puzzling, powering and participation. Bristol: Policy Press.

Hoppe, R., \& Hisschemoller, M. (1995). Coping with intractable controversies: the case for problem-structuring in policy design. Knowledge for Policy, 4(8), 40-60.

Huq, S., \& Reid, H. (2007). Community-based adaptation: A vital approach to the threat climate change poses to the poor. London: International Institute for Environment and Development. 
Huq, S., Reid, H., Konate, M., Rahman, A., Sokona, Y., \& Crick, F. (2004). Mainstreaming adaptation to climate change in least developed countries (LDCs). Climate Policy, 4(1), 25-43.

IPCC. (2014). Climate change 2014: Synthesis Report. Contribution of Working Groups I, II and III to the Fifth Assessment Report of the Intergovernmental Panel on Climate Change [Core Writing Team, R.K. Pachauri and L.A. Meyer (eds.)]. Geneva: IPCC.

Ishtiaque, A., Sangwan, N., \& Yu, D. J. (2017). Robust-yet-fragile nature of partly engineered social-ecological systems: a case study of coastal Bangladesh. Ecology and Society, 22(3), 5.

Islam, M. S. (2008). In search of "white gold": Environmental and agrarian changes in rural Bangladesh. Society and Natural Resources, 22(1), 66-78.

Islam, R., \& Walkerden, G. (2015). How do links between households and NGOs promote disaster resilience and recovery?: A case study of linking social networks on the Bangladeshi coast. Natural Hazards, 78(3), 1707-1727. https://doi.org/10.1007/s11069-015-1797-4.

Jaeger, M. D., \& Michaelowa, K. (2016). Global climate policy and local energy politics: Is India hiding behind the poor? Climate Policy, 16(7), 940-951.

Jain, M., Naeem, S., Orlove, B., Modi, V., \& DeFries, R. (2015). Understanding the causes and consequences of differential decision-making in adaptation research: Adapting to a delayed monsoon onset in Gujarat, India. Global Environmental Change, 31, 98-109.

Jogesh, A., \& Dubash, N. K. (2015). State-led experimentation or centrally motivated replication? A study of state action plans on climate change in India. Journal of Integrative Environmental Sciences, 12(4), 247-266.

Jorgensen, K., Mishra, A., \& Sarangi, G. K. (2015). Multi-level climate governance in India: the role of the states in climate action planning and renewable energies. Journal of Integrative Environmental Sciences, 12, 267-283.

Khan, M. R., \& Rahman, M. A. (2007). Partnership approach to disaster management in Bangladesh: A critical policy assessment. Natural Hazards, 41(2), 359-378. https://doi.org/10.1007/s11069-006-9040-y.

Lukes, S. (2005). Power: A radical view (2nd ed.). Basingstoke: Palgrave MacMillan.

Majone, G. (1998). Public Policy and Administration: Ideas, Interests and Institutions. In R. E. Goodin (Ed.), A new handbook of political science (Vol. 1, pp. 610-628). Oxford: University Press.

Mathew, S., Truck, S., \& Henderson-Sellers, A. (2012). Kochi, India case study of climate adaptation to floods: Ranking local government investment options. Global Environmental Change-Human and Policy Dimensions, 22, 308-319.

Mehta, L. (2009). Displaced by development: Confronting marginalisation and gender injustice (pp. 59-81). New Delhi: Sage Publications.

Meijer, K. S., \& Van Beek, E. (2011). A framework for the quantification of the importance of environmental flows for human well-being. Society and Natural Resources, 24(12), 1252-1269.

Modi, N. (2011). Convenient action: Gujarat's response to challenges of climate change. New Delhi: Macmillan.

MOEF (2009) Bangladesh Climate Change Strategy and Action Plan 2009. Ministry of Environment and Forests Government of the People's Republic of Bangladesh, Dhaka, Bangladesh.

MOEF, (2017). State Action Plan on Climate Change. Ministry of Environment, Forest and Climate Change. New Delhi: Government of India. Retrieved 1 September 2017.

Nagoda, S., \& Nightingale, A. J. (2017). Participation and power in climate change adaptation policies: Vulnerability in food security programs in Nepal. World Development, 100, 85-93.

Newton, P., Fournier, M., Cornwall, M., DeBoer, J., Rosenbach, D. W., Schaap, B., et al. (2015). Community forest management and REDD+. Forest Policy and Economics, 56, 27-37. https://doi. org/10.1016/j.forpol.2015.03.008.

Nightingale, A. J. (2011). Bounding difference: Intersectionality and the material production of gender, caste, class and environment in Nepal. Geoforum, 42, 153-162.

Nightingale, A. J. (2017). Power and politics in climate change adaptation efforts: Struggles over authority and recognition in the context of political instability. Geoforum, 84, 11-20.

O’Donnell, M., Rashid, A. M., Steele, P., Hedger, M., Lee, J., Islam, K. M. N., et al. (2013). Bangladesh climate public expenditure and institutional review. Climate change adaptation actions in Bangladesh (pp. 365-385). Japan: Springer.

O’Keefe, P., Westgate, K., \& Wisner, B. (1976). Taking the naturalness out of natural disasters. Nature, 260, $566-567$.

O’Brien, K., Eriksen, S., Nygaard, L. P., \& Schjolden, A. (2007). Why different interpretations of vulnerability matter in climate change discourses. Climate Policy, 7(1), 73-88.

Phadke, R. (2005). People's science in action: The politics of protest and knowledge brokering in India. Society and Natural Resources, 18(4), 363-375. 
Rahman, M. S., \& Tosun, J. (2018). State bureaucracy and the management of climate change adaptation in Bangladesh. Review of Policy Research, 35, 835-858.

Rai, P., \& Smucker, T. A. (2016). Empowering through entitlement? The micro-politics of food access in rural Maharashtra, India. Journal of Rural Studies, 45, 260-269.

Ramanujam, R. V., Singh, S. J., \& Vatn, A. (2012). From the ashes into the fire? Institutional change in the post-tsunami Nicobar Islands, India. Society and Natural Resources, 25(11), 1152-1166.

Rashid, H. (2011). Media framing of public discourse on climate change and sea-level rise: Social amplification of global warming versus climate justice for global warming impacts. In M. Hossain \& E. Selvanthan (Eds.), Climate change and growth in Asia. Cheltenham: Edward Elgar.

Rastogi, A., Thapliyal, S., \& Hickey, G. M. (2014). Community action and tiger conservation: Assessing the role of social capital. Society and Natural Resources, 27(12), 1271-1287.

Remling, E., \& Persson, A. (2015). Who is adaptation for? Vulnerability and adaptation benefits in proposals approved by the UNFCCC Adaptation Fund. Climate and Development, 7, 16-34.

Ribot, J. (2010). Vulnerability does not fall from the sky: Toward multi-scale, pro-poor climate policy. Social Dimensions of Climate Change: Equity and Vulnerability in a Warming World, 2, 47-74.

Ribot, J. (2014). Cause and response: Vulnerability and climate in the Anthropocene. Journal of Peasant Studies, 41(5), 667-705.

Ribot, J., \& Larsen, A. (2005). Democratic decentralisation through a natural resource lens. NY: Routledge.

Rose, G. (2001). Visual methodologies: An introduction to the interpretation of visual materials. London: Sage.

Safi, M. (2017). India floods: 213 killed in Gujarat as receding waters reveal more victims. The Guardian. Retrieved from https://www.theguardian.com/world/2017/jul/31/india-monsoon-floods-gujar at-death-toll-over-200.

Sayer, R. (2000). Realism and social science. London: Sage.

Shackleton, S., Ziervogel, G., Sallu, S., Gill, T., \& Tschakert, P. (2015). Why is socially-just climate change adaptation in sub-Saharan Africa so challenging? A review of barriers identified from empirical cases. Wiley Interdisciplinary Reviews: Climate Change, 6(3), 321-344.

Sherman, M., Berrang-Ford, L., Lwasa, S., Ford, J., Namanya, D. B., Llanos-Cuentas, A., et al. (2016). Drawing the line between adaptation and development: A systematic literature review of planned adaptation in developing countries. Wiley Interdisciplinary Reviews-Climate Change, 7, 707-726.

Smit, B., \& Wandel, J. (2006). Adaptation, adaptive capacity, and vulnerability. Global Environmental Change, 16, 282-292. https://doi.org/10.1016/j.gloenvcha.2006.03.008.

Sovacool, B. K. (2018). Bamboo beating bandits: Conflict, inequality, and vulnerability in the political ecology of climate change adaptation in Bangladesh. World Development, 102, 183-194.

Stock, R., \& Birkenholtz, T. (2019). The sun and the scythe: Energy dispossessions and the agrarian question of labor in solar parks. The Journal of Peasant Studies. https://doi.org/10.1080/03066 150.2019.1683002.

Stock, R., Birkenholtz, T., \& Garg, A. (2019). Let the people speak: Improving regional adaptation policy by combining adaptive capacity assessments with vulnerability perceptions of farmers in Gujarat, India. Climate and Development, 11(2), 138-152. https://doi.org/10.1080/17565529.2017.1410089.

Sultana, F. (2014). Gendering climate change: Geographical insights. Professional Geographer, 66(3), $372-381$.

Taylor, M. (2015). The political ecology of climate change adaptation. New York: Routledge.

Thornton, P. K., Ericksen, P. J., Herrero, M., \& Challinor, A. J. (2014). Climate variability and vulnerability to climate change: a review. Global Change Biology, 20(11), 3313-3328.

van der Steen, M., Chin-A-Fat, N., Vink, M., \& van Twist, M. (2016). Puzzling, powering and perpetuating: Long-term decision-making by the Dutch Delta Committee. Futures, 76, 7-17.

Vij, S., Biesbroek, R., Groot, A., \& Termeer, K. (2018). Changing climate policy paradigms in Bangladesh and Nepal. Environmental Science and Policy, 81, 77-85.

Vij, S., Biesbroek, R., Groot, A., Termeer, K., \& Parajuli, B. P. (2019). Power interplay between actors: using material and ideational resources to shape local adaptation plans of action (LAPAs) in Nepal. Climate Policy, 19(5), 571-584.

Vij, S., Moors, E., Ahmad, B., Uzzaman, A., Bhadwal, S., Biesbroek, R., et al. (2017). Climate adaptation approaches and key policy characteristics: Cases from South Asia. Environmental Science and Policy, 78, 58-65.

Vink, M. J., Benson, D., Boezeman, D., Cook, H., Dewulf, A., \& Termeer, C. (2015). Do state traditions matter? Comparing deliberative governance initiatives for climate change adaptation in Dutch corporatism and British pluralism. Journal of Water and Climate Change, 6(1), 71-88. 
Vink, M. J., Boezeman, D., Dewulf, A., \& Termeer, C. J. A. M. (2013a). Changing climate, changing frames: Dutch water policy frame developments in the context of a rise and fall of attention to climate change. Environmental Science and Policy, 30, 90-101.

Vink, M., Boezeman, D., Dewulf, A., Termeer, C. (2014). Action research in governance landscapes. In Action research for climate change adaptation: Developing and applying knowledge for governance; Routledge: Abingdon-on-Thames, 35.

Vink, M. J., Dewulf, A., \& Termeer, C. (2013b). The role of knowledge and power in climate change adaptation governance: a systematic literature review. Ecology and Society. https://doi.org/10.5751/ ES-05897-180446.

Visser, J., \& Hemerijck, A. (1997). A Dutch miracle: Job growth, welfare reform and corporatism in the Netherlands. Amsterdam: Amsterdam University Press. https://doi.org/10.5117/9789053562710.

Watts, M. (1983). On the poverty of theory: natural hazards research in context. In K. Hewitt (Ed.), Interpretation of calamity (pp. 23-62). Boston: Allen and Unwin.

Watts, M. J., \& Bohle, H. (1993). The space of vulnerability: The causal structure of hunger and famine. Progress in Human Geography, 17(1), 43-68.

Publisher's Note Springer Nature remains neutral with regard to jurisdictional claims in published maps and institutional affiliations.

\section{Affiliations}

\section{Ryan Stock ${ }^{1}$ (D) Sumit $\mathrm{Vij}^{2,3}$ (D) Asif Ishtiaque ${ }^{4,5}$}

Ryan Stock

rystock@nmu.edu

Asif Ishtiaque

asif.ishtiaque@asu.edu

1 Department of Earth, Environmental and Geographical Sciences, Northern Michigan University, 1401 Presque Isle Ave., Marquette, MI 49855, USA

2 Public Administration and Policy Group, Wageningen University and Research, Wageningen, The Netherlands

3 Earth and Climate cluster, Vrije Universiteit, Amsterdam, The Netherlands

4 School of Geographical Sciences and Urban Planning, Arizona State University, Tempe, AZ 85281, USA

5 School for Environment and Sustainability, University of Michigan, Ann Arbor, MI 48109, USA 